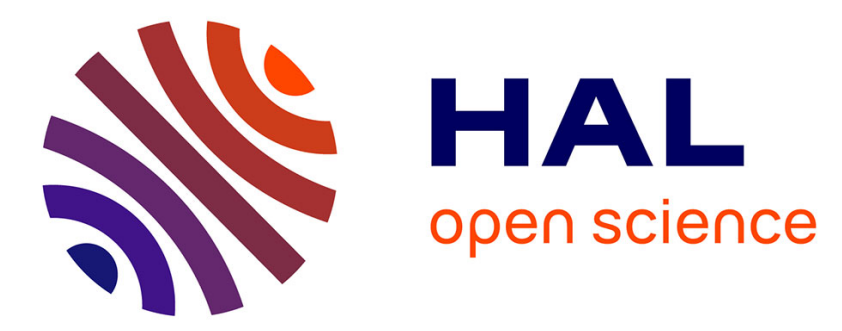

\title{
Introducing the wave of prosumers in the age of labour market shattering
}

\author{
Davide Arcidiacono, Allison Marie Loconto, Lara Maestripieri, Antonello \\ Podda
}

\section{To cite this version:}

Davide Arcidiacono, Allison Marie Loconto, Lara Maestripieri, Antonello Podda. Introducing the wave of prosumers in the age of labour market shattering. Sociologia del Lavoro, 2018, 152, pp.7-22. 10.3280/SL2018-152001 . hal-02048858

\section{HAL Id: hal-02048858 \\ https://hal.science/hal-02048858}

Submitted on 25 Feb 2019

HAL is a multi-disciplinary open access archive for the deposit and dissemination of scientific research documents, whether they are published or not. The documents may come from teaching and research institutions in France or abroad, or from public or private research centers.
L'archive ouverte pluridisciplinaire HAL, est destinée au dépôt et à la diffusion de documents scientifiques de niveau recherche, publiés ou non, émanant des établissements d'enseignement et de recherche français ou étrangers, des laboratoires publics ou privés. 


\title{
Introducing the wave of the prosumers in the age of labour market shattering
}

\author{
Davide Arcidiacono*, Allison Loconto**, \\ Lara Maestripieri ${ }^{* * *}$, Antonello Podda ${ }^{* * * *}$
}

\section{Prosumption as an analytical tool}

While economics was the first to acknowledge the centrality of consumers as a category of actors in markets, mainly as the driver of demand for the supply side of the equation, it also enshrined their "instrumental subordination" to production. Economists confined consumers to a role of simply choosing goods and services and contributing to their final "destruction". According to this approach, production and consumption are two distinct but communicating arenas, mediated through market institutions. Here, consumers and producers act on the basis of their own non-commensurable prerogatives, motivations and repertoires. This vision of the market and its actors has been culturally dominant in twentieth-century industrial capitalism, and in much of the scientific debate on the figure of the consumer up until the first half of the twentieth century.

However, as early as the 1930 s, scholars pointed out the fragility of such an approach. Chester Barnard (1938), who argued for a notion of production as a cooperative system, was one of the first to refer to consumers not as simple "selectors", sovereign or manipulated, but as almost-employed actors. In his studies on tertiarization Parsons (1970), underlined the centrality of

\footnotetext{
${ }^{*}$ Department of Sociology. University Cattolica del Sacro Cuore of Milan. Davide Arcidiacono is the author of the paragraph 1 and 2 of this introduction.

** Interdisciplinary Laboratory for Science, Innovation and Society (LISIS), National Institute for Agricultural Research (INRA), University of Paris-Est Marne-la-Vallée; JFK School of Government, Harvard University. Allison Marie Loconto is the author of paragraph 5 and contributed text to all paragraphs. ${ }^{* * *}$ Lara Maestripieri is the author of paragraph 3.

**** Department of Social and Institutional Sciences. University of Cagliari. Antonello Podda is the author of paragraph 4.
} 
participation and involvement of consumers in the production process. However, cultural studies were finally able to overcome this analytical dichotomy through the analysis of the intersections between production, mass media communication and consumption. This body of literature developed by assuming an active and creative role for consumption, shifting attention from choices to practices, as has been systematized in the so-called Consumer Culture Theory (CCT). With CCT,Arnould and Thompson (2005) explored the intersections between production and consumption in a research agenda able to relate history and market building ( and in particular, the formation of niches in an increasingly segmented market) with the processes of interpretation, signification and identity building of consumers. This research agenda tried to demonstrate how consumers, through their own practices, regained the possession of the semantic dimension of goods, reframing signs and symbols (demercification) in some way contrasting demands and aims of the producer.

The term prosumer was coined by Arvin Toffler (1980), who repositioned the consumer as central to markets and introduced a new hybrid actor, formed from the terms producer + consumer. Through this term, Toffler emphasized how the growing need for differentiation and customization would effectively reduce the gap between production and consumption, bringing capitalism into a new phase in which identities, repertoires and goals of the two actors ended up overlapping and integrating. The new hybrid economic actor is thus sustained by the processes of technological innovation and, in particular of mass communication technology which are credited for the transition from the first wave (with the advent of writing and the printing system) to the second wave (the era of radio and television), highlighting the advent of a third wave of self-media in which the user was also the producer of the messages.

The digital transformation and the advent of web 2.0 has concretised the need to re-frame the concept of consumer. Incorporating Toffler's intuition, the conceptual category of prosumer is essential to understanding the processes of economic transformation in the $21^{\text {st }}$ century. We see this also captured by Bruns' (2008) term prod-user, that describes the user generated content phenomenon of you-tubers, which shows how the boundaries between production and consumption have become fluid. Prosumers aren't just a producer of messages or, as Arvidsson (2013) argues, merely "productive publics" (p. 63). Rather, as Campbell (2005) pointed out, we are talking about a craft consumer, a subject that reinterprets and processes goods as if they were semi-finished products to be completed. Prosumers 
model, following subjective and creative itineraries, and increasingly provide direct and indirect stimuli to product and process innovations.

Nonetheless, he role of consumers in the division of labour is rarely acknowledged in theories of work/production, despite the fact that the work of consumers was always relevant in its various forms (paid/unpaid; formal/informal; autonomous/dependent). According to Glucksmann (2016), it is impossible to ignore the value of the work of the consumer because:

- there are only a few products / services that are directly consumable; the consumer almost always does something that integrates the work of the seller;

- consumption is based on the acquisition of knowledge and skills, sometimes even formally certified (think of driving licenses to use a car);

- consumption needs coordination with producers in order to develop coherence and complementarity with the previous or subsequent phases in the lifecycle of a product (production, distribution, disposal);

- consumption can be "outsourced", in the event that consumers do not or do not want to participate in the production process (think of home delivery or IKEA's new assembly service).

The analytical revolution of the prosumer has been taken up by marketing and managerial disciplines, more than it has been done by economic and labour sociology, especially in Italy. Starting from the early works of Holbrook and Hirschman (1982), up to the construction of specific approaches such as experiential marketing (2004), service quality management (Parasuraman, Zeithaml and Berry, 1985), corporate social responsibility (Drucker, 1984) and service dominant logic (Vargo and Lasch, 2006), the notion of a consumer has changed. In this literature, we now see a recognition of consumers as stakeholders - on par with suppliers, partners or employees - or as cooperating actors in terms of resources, skills and abilities, the value creation.

However, simply recognizing the hybrid producing consumer doesn't necessarily end power asymmetries, inequalaccess to information or ownership of the means of production between producers and customers. Rather, looking at how these asymmetries are re-configured in order to bring new opportunities and create new risks of inequality needs more attention by economic sociologists. Rethinking consumer agency and the integration of consumers into the production process can bring to light the positive effects like the innovations of sharing economy (Schor, 2014). It can also reveal strong critiques of the dominant production models (De Certau, 2001) and provide space for proposals for alternative productive paradigms, such as 
political consumerism (Micheletti et al., 2005; Arcidiacono, 2013) and alternative food networks (Whatmore et al., 2003; Forno and Graziano, 2016). This re-conceptualisation of the consumer can also introduce new forms of exploitation, as Fuchs (1968) warned, where consumers are coopted in the standardization and the contingency of capitalist production (Ritzer and Jungerson, 2010), while receiving no rewards for their efforts and even competing with the formalised workforce (Dujarier, 2009).

While public discourse has taken up these concerns, many questions remain to be answered in the social sciences, such as: what is the disruptive capacity of these practices in terms of whole systems and institutions? What is their real impact, and on whom? How are they changing the worlds of production and work? What are the types of regulatory challenges that they raise and how are institutions responding? Can they bring more sustainable, equitable and responsible practices to future society

This fluidity of boundaries between production and consumption and its consequences for the organisation of society should be at the centre of analysis in the sociology of work, and this special issue is a first step in this direction. Here, we collect theoretical and empirical papers from Italian and International scholars that investigate, from a variety of critical perspectives, the nature of presumption in the current economy. We focus on both the transformation of the productive role of consumers and the reshaping of economic paradigms. The issue is separated in three theoretically contingent sections: 1) the "Redefinition of boundaries between consumption and work: working for/as/with the consumers"; 2) "The sharing economy and the role of prosumers in the platform paradigm"; and finally, 3) "Prosumers and Welfare innovation". Each section contains articles that contribute to our understanding of these phenomena in different economic spheres. We explore each in turn.

\section{The new organisational design of the boundaries between work and consumption}

The first section deals with new organisational designs that blur the boundaries between work and consumption. While the concept of prosumer developed to explain what new media did to notions of work, the concept promises a real rethinking of the logics of production and the creation of value. Even if historically a large part of consumers' work had been confined to an informal status and was mostly unpaid, today there are entire sectors that are built on the work of consumers. Thus, a challenge for productive 
organisations is figuring out how to integrate consumers' work. As companies begin to formalise and codify the role of consumers, this is not always accomplished in monetary terms. For example, in the green economy (production of energy from renewable sources, recycling, etc.), healthcare or mobility.

The formal and systematic inclusion of the consumer in the production process can be (Arcidiacono, 2017):

- hierarchical, maintaining a certain asymmetry between the company and the consumer in relation to the objectives and tools to be adopted, as in the case of crowdsourcing;

- or equal and horizontal, for which consumers produce not for the purpose of individual appropriation but to generate shared benefits, as in the case of open content systems;

- individual, in the case of the self-service economy or the do it yourself economy (i.e.: IKEA);

- or, collaborative, as in the case of collaborative consumption, or of peer to peer production (i.e.: file sharing).

A common recent organizational design is that of a platform structure. (Kenney and Zysman, 2016). Here, a central system (not only digital) engages and coordinates diversified production systems and diverse networks of human and non-human co-operators (either professional or amateur). The company does not necessarily or directly supply products or services designs and builds the environment in which the interactions that underlie it take place. Therefore, the organisation is more an enabler of distributed, hybrid and flexible production processes rather than a producer or even trader. It is a heterarchical model of organisation (Stark, 1996), opposed to the rigidly hierarchical and pyramidal models of the Fordist tradition. also It is also different from the ordered reticular type of the Toyota-ist paradigm or systemically linked as in the industrial districts. In heterarchies, decision-making processes and the benefits derived from it, are distributed and shared (even if not always fairly), so that organisation tends to go far beyond its formal boundaries. It is a "möbius organization" (Stark and Watkins, 2018), an organisational system based on the co-optation (sometimes even aggressive) of assets and resources without any alliance or fully formalised constraints. Taking a step further than those systems based on integration between making, buying or cooperating (Kogut et al., 1992).

The innovative capacity of this model is measured precisely by the possibility of creating spaces for expressive and creative production that are widespread in the network and transformed into value for the company. The company is thus transformed into an "open system" in which its innovative 
capacity lies in including (but also in extracting value from) actions, relationships, projects and creativity scattered across the network.

The modern large-scale retail sector is one of the most evident cases of organizational transformation crossed by the third wave of prosumers. The passage has extended the capacity of consumers to freely access goods within the store, reconfiguring the traditional role of the sales employee. This employee no longer mediates access to goods, because the consumer has all the necessary information and has already largely solved selection dilemmas, but he becomes a professional of the relationship. Fullin and Coletto (this issue) argue that this would not have led to a process of substitution of formal work with informal consumer work, but rather, it would have affected the aims and contents of the sales work itself. The sales employee brings into play his personal and emotional dimension, helping to build the sales experience with the consumer. The latter becomes the new "object" of the company's production, and at the same time the parameter to evaluate the quality of work for both the employee and the employer.

However, the situation changes radically passing from the retail sector, to the event management sector, as in the case of the promotion of the Milan Design Week (Cossu, this issue). In this case study, the customer participation and customer connection through social media is an integral part of the production process. The brand of the event is transformed into a symbolic communicative infrastructure that directs and nourishes information flows and content created directly by the participants. Following from the Fullin and Coletto article, we move from the dimension of working for the consumer to working as a consumer.

Reckinger (this issue) introduces the analytical concept of alternative roleplayers as she explores diverse yet complementary food production and retail niches. She argues that neither the timing (old/new) nor the duration (short/long) of food activism accounts for how many compromises have to be accepted by consumers and producers in order for the production logics to be valued. However, the organisational structure does make a difference. A community supported agriculture (CSA) model with captive customers is more reliable and simpler to implement than classic transactional selling with a central procurement platform. This study also finds that the more direct the prosumer involvement, the less dispersion (dilution) of standards. This was found both in the 'disintermediated' CSA models and in the retail with prosumer commitment models. The reflexive work of the prosumer within thus becomes dialogical, where the consumer also engages in the negotiation and reframing work of enacting the alternatives. 
De Chiara (this issue) drops the last taboo on prosumers, as she explores a phenomenon that also requires public production. This change overcomes the idea of a public administration as a closed and self-referential organisation in which public actors and citizen-consumers are inevitably destined to a dichotomy of roles. Traditionally, this separation was mainly guaranteed by the principle of public information confidentiality. With the emergence of the Open Data phenomenon, based on the sharing of public sector information, the public administration opened its organisational structure. It began working with its own citizens/consumers, who co-created new services and, at the same time, it provided essential resources that could be used to build innovative self-entrepreneurship paths in the knowledge economy.

\section{Sociability, trust and social capital of prosumers in the sharing economy platform}

The second section consists of papers that explore the types of trust and social capital that prosumers construct in these new organizational forms, particularly in what has been referred to as the sharing economy. The concept of the sharing economy is broad and includes a plurality of exchange practices, often very different in their goals and mechanisms (Shor, 2014). It began through the experiences of the community time banks which were basically founded as a way to contrast the commodification of time and create new relations between people from the same community (New Economics Foundation, 2001). Although these are considered innovative and important experiences of the sharing economy, they did not spread widely and remained locally confined in a small community. Nowadays, through the technological evolution and the widespread diffusion of the internet, we are witnessing an enlargement of sharing economy experiences, with ondemand platforms, open source software communities and collaborative platforms (Pais e Provasi, 2015). Well known cases are, for example, Gnammo and, BlaBlaCar, or "on-line time banks" like Timerepublik (Seyfang, 2004; Dittmer, 2013; North, 2014; Laamanen, Wahlen \& Campana, 2015; Arcidiacono and Podda, 2017). In all these cases the sharing economy can be indicated as an exemplary case of hybridization between production and consumption.

The sharing economy is also a mix of innovation and tradition in which the classical sociological analysis of the mechanisms of human action is renewed and updated. It re-emphasizes the Polanyan concept of reciprocity of relations (Pais and Provasi, 2015; Arcidiacono and Podda, 2017), and trust 
in exchange relationships (Gambetta, 1988). At the same time, a new legitimacy is given to the notion of the embeddedness of economic action (Granovetter, 1985) and the analysis of social capital (Boyle, 2003). Thus, if at the micro level prosumers are often oriented by value and motivation (Arcidiacono, 2013), then at the macro level sharing economy platforms have a powerful role in stimulating relationships between actors and creating new levels of mutual trust. This might occur hypothetically by incentivising those socially shared "correct behaviours"; and disincentivising the utilitarian use of the platforms themselves. These practices might be considered as a practice of "re-socialising economic exchange" (Belk, 2014), but in many cases there is a risk that the "sharing label" will be applied to organisations or companies that have only economic goals, thus distorting the concept of the sharing economy.

This opens the empirical question of what is a sharing economy? Botsman and Rogers (2010) defines the sharing economy as an «economic model based on collaboration and sharing of assets, spaces, skills, objects, in order to derive monetary benefits and not». At the same time, a sharing process presupposes a horizontal and circular production model that tries to disintermediate and cancel the differences between those who produce, distribute or consume a service (Arcidiacono, 2013). One of the main questions that must be asked when studying the sharing economy platforms is the following: this platform, in addition to being a way to save money for consumers - is it able to stimulate the creation of solidarity relationships, trust and ties that go beyond the single spot transaction?

Three articles in this special issue respond to this question by highlighting the relational, personal and social aspects of prosumption and furthers knowledge about the creation and maintenance of trust in sharing relationships. Andreotti, Anselmi, and Hoffmann (this issue) examine the creation of social capital by the work of prosumers in sharing economy platforms. They use the definition "work of users" (Glucksmann, 2016) to describe the role of users as active and fundamental as producers of information. The information users collect and produce in the digital platform can be considered a specific kind of work that «enables the functioning of sharing platforms, as they dedicate a sizable amount of time to read reviews to select a suitable partner to exchange with». While simultaneously interrogating the concept of social capital itself, the authors clarify the functioning of information on the reputation and reliability of users in sharing platforms. They explain how this operation allows the creation of those "weak ties" that constitute a peculiar and useful form of social capital. The qualitative analysis deepens the motivational aspects of 
the transactions, and investigates how, beyond the economic aspects, users expect emotional work from other users. This transforms the economic transaction into an interpersonal social exchange. Thus, even in "loose community" sharing some common values and fostering of cooperative relations is fundamental for the creation of weak ties and social capital.

Setiffi, Lazzer, and Scotto (this issue) deepens the different levels of commitment among people involved in sharing practices. It analyzes, at the micro level, three different platforms of the sharing economy, BlaBlaCar, Airbnb, and Gnammo. The basic idea is that different platforms imply different levels of sociability involved in the interaction among prosumers. Thanks to the large qualitative analysis of 128 semi-structured interviews with consumers of the sharing experiences, the authors can define three different kinds of prosumers, linked to different levels of skills and personal investment in the sharing action. These are also related at different levels of "professionalisation", which in turn are linked to different kinds of relational intensity.

Spillare, Paltrinieri, and Marciante (this issue) also pick up the platform model (Civic Food Platforms, CFPs) in order to understand the offline and online trust building processes that enable the enrolment of consumer work in Civic Food Networks (CFNs). The authors find that the platform models of organization are able to expand the producers' networks to reach more consumers (structural social capital), but these are more 'traditional' and less 'active' than those who are also involved in community engagement around food. In the cases examined in this article, it seems that platforms can rely upon money and automatic systems that measure digital reputation via algorithms as a means to create trust between producers and consumers - but when they do, the consumers become less prosumers and slip back into the traditional role of simple consumption.

The three abovementioned articles, reach similar conclusions. Even if it is economic motivation that pushes actors to use the sharing economy platforms, the relationships among the actors create immaterial results $-\mathrm{a}$ range of levels of sociality, trust, and social capital. When the platforms work well, these relationships can increase creating a virtuous circle with the platform. In other words, the sharing economy model works if it is able to re-socialize (Belk, 2010) the economic exchange.

\section{Prosumption as a practice of welfare innovation: improved participation or increased inequalities?}


The concept of prosumers can be fruitfully applied to the analysis of the contemporary transformation of welfare, in which the "social innovation" turn (Moulaert et al, 2013; Ziegler, 2017) stresses the involvement of multiple actors and the participation of citizens in the definition of social policies and delivery of welfare services, especially at local level. Prosumption, in the case of welfare, is defined by the expansion of welfare beneficiaries' agency. The idea is that it disrupts the traditionally top-down service-provision approach by stimulating a bottom-up process where citizens actively co-produce their welfare together with third sector organizations, private funders and the State. Thus, public actors assume the role of an enabler more than a provider. This regulatory approach favours the mobilisation of "hidden resources" from civil society and its capacity to represent the diversity and liveliness of the local context in which the welfare innovation is proposed. Citizens not only participate directly as activated beneficiaries: they also participate indirectly via civil society organizations, in associations that promote culture or social initiative and as third sector operators. The stated advantage of prosumption is that citizens can regain their voice, empower their own autonomy and actively shape how the services they need are provided by the welfare system. But, empirical studies are increasingly challenging the rhetoric of social innovation (Pol and Ville, 2009) and more evidence is needed to contest the taken-for-granted positivity of change, which has encourage a pro-profit turn in a sector that deals with the fundamental needs of citizens (Maier et al, 2016).

In this special issue, the two papers contained in this third section illustrate best practices of innovation at the local level, showing at the same time the limits of the spread of prosumption in the welfare sector. The articles both examine attempts to improve the participation of citizens and to empower citizens addressing welfare services, thanks to the development of e-government platforms (as in the WeGovNow and We.Mi projects analysed by Visentin) or to the co-design approach to housing (as in the five experiences proposed by Bernardi, Iaione and Prevete).

The practices described in the two papers increasingly show how the boundaries between welfare providers and those who benefit from the welfare services are blurred. Far from being separate entities, the citizens are requested to be active in the definition of the service they need. Thus, the 'consumers of welfare' are becoming cooperating actors, at least passively through the choice of the providers as in the We.Mi project; or actively by participating in the definition of the required housing services as in Cenni di Cambiamento. Citizen-engagement goes up to point that they actively work 
to ensure the provision of the services, with the risk of exploitation that free (or very low paid) labour brings with it.

Moreover, a neoliberal logic is becoming dominant in the idea that different types of welfare providers (public, private, third sector) should compete via platforms - as in the case of $\mathrm{We} . \mathrm{Mi}$ - in order to attract their own beneficiaries - respecting the freedom to choose the service that best fits the citizens' needs. But a market-like mechanism also presupposes that citizens can go through all the process of selection and co-production without the support of public specialised operators. The inherent risk is that of enabling only the least marginalised and the most capable among the citizens in need accessing platforms, leaving aside those who cannot grasp the technology behind it and the complexity of the choice. Theoretical debates about welfare mix (Ascoli, 2003) and new mutualism (Lodigiani, 2016) have already raised concerns about the fact that welfare innovations might generate new inequalities instead of improving equality and inclusion of marginalised citizens.

The rhetoric of social innovation has been strong in promising the democratization of welfare determined by the increased activation and participation of recipients, but it has been also instrumentally applied in the context of retrenchments to cover the progressive de-responsabilisation of public actors in the provisions of goods and services (Oosterlynck et al, 2013). The support that municipalities have given in the last years to innovative experiences of welfare provisions has also been accompanied by the reduction of direct public investments in traditional welfare solutions. When resources for welfare are tight, requirements for accessing services becomes extremely selective, targeting only populations that have multiple problems, while leaving out of support the least vulnerable among the citizens in need. For instance, Bernardi, Iaione and Prevete stress how innovative practices of co-housing are developed to meet the housing needs of those citizens who are left out of the system of public housing, which is underfinanced and able to meet the demands only from the most socially excluded cases.

The reduced role of the State is supposedly partially compensated by civil society and private actors, but more welfare actors don't necessarily imply more homogenous support for all the citizens. The case selection proposed in the two paper puts into evidence how the economic performance of the localities are determinant in favouring the establishment of these innovative practices. Not by chance, the cases discussed in the two papers are located in the North and Centre of Italy, where there is a virtuous circle of private funders, strong associative context and the capacity to attract private funding. 
This allows innovative welfare solutions to be invented, supported and implemented. Established financial actors like Cariplo Foundation, Lucca Cassa di Risparmio or Compagnia di San Paolo are fundamental for the development of the welfare practices presented in the two articles, necessarily configuring a fragmented panorama across Italy, with the South twice as disadvantaged with a higher presence of citizens in need and a lower presence of potential funders. In addition, the smallest localities are only rarely able to benefit from the economies of scales necessary to develop the innovative practices, even though both articles describe best practices from medium towns like San Donà di Piave or Fidenza. Nonetheless, they are exceptions, in a landscape dominated by cities like Milan, Turin or Bologna.

Last but not least, the most innovative and disruptive cases - like Ecosol in Fidenza or A casa di Zia Gessy in Torino - are able to involve only a very small number of participants. This seriously puts into question the capacity of the proposed solutions to scale-up and be implemented to meet the need of the proposed targets on a wider scale. If prosumption is in theory a winwin game for all actors involved, due to improved participation and the democratization of welfare, it is also important not to forget at what cost such innovation is produced. These papers also identify some negative effects of presumption, such as: an increased differentiation among municipalities and areas; the systematic exclusion of certain populations due to technological barriers of access or the limited number of possible beneficiaries; and the risk of labour exploitation derived from the rhetoric of prosumption (mentioned above but also applicable here). The explored in this third section have to be considered opportunities for innovating certain modalities of services provisions, but they cannot substitute the fundamental role that the public sector still has to play in equally guaranteeing to all citizens the satisfaction of their basic needs.

\section{Conclusions}

This collection of empirical and theoretical articles barely scratches the surface of questions that emerge from the collapsing of production and consumption activities, roles and agencies. Specifically, the types and categories of work and workers that we explore here offer exciting avenues for the sociology of work in so far as the questions of: who can be trusted in the new platform and sharing economies? what is being produced when prosumers are increasingly active in the productive work? what allocation of roles and responsibilities in service provision are most equitable and inclusive? And what does all of this mean for the changing nature of the work 
required by 'traditional' producers and services providers? These and many more questions are ripe for investigation in the sociology of work.

\section{References}

Arcidiacono D. (2013). Consumatori Attivi. Scelte d'acquisto e partecipazione per una nuova etica economica. Milano: Franco Angeli.

Arcidiacono D. (2017). L'inclusione del consumatore nella catena del valore. In Barbera F. and Pais I., (a cura di), Fondamenti di Sociologia Economica. Milano: Egea.

Ascoli U. (2003) Il Welfare mix in Europa. Roma: Carocci Editore.

Arnould E.J. and Thompson C. J. (2005). Consumer Culture Theory (CCT): Twenty Years of Research. Journal of Consumer Research, 31 (4): 868-882. DOI: 10.1086/426626.

Arvidsson A. (2013). Pubblici Produttivi. In: Arvidsson A. e Giordano A., a cura di, Society Reloaded. Pubblici Produttivi e Innovazione Sociale. Milano: Egea.

Barnard C. (1938). The function of executive. Cambridge: Harvard University Press.

Bruns A. (2008), Blogs, Wikipedia, Second Life and Beyond: from Production to Produsage, New York: Lang Publishing.

Campbell C. (2005). The Craft Consumer. Journal of Consumer Culture, 5 (2): 131-153.

De Certau M. (2001). L'invenzione del quotidiano. Edizioni Lavoro: Roma.

Drucker P. F. (1984). Converting social problems into business opportunities: The new meaning of corporate social responsibility. California Management Review, 26(2):53-63. DOI: $10.2307 / 41165066$.

Dujarier M. A. (2009), Il lavoro del consumatore. Come co-produciamo ciò che compriamo, Milano: Egea.

Forno F. and Graziano P.R. (2016). Il consumo critico. Una relazione solidale tra chi acquista e chi produce. Bologna: Il Mulino.

Fuchs V. (1968). The service economy. New York: Columbia University Press.

Glucksmann M. (2016) Completing and Complementing: The Work of Consumers in the Division of Labour. Sociology, 50(5): 878-895.

Holbrook M.B. and Hirschman, E. C. (1982). The Experiential Aspects of Consumption: Consumer Fantasies, Feelings, and Fun. Journal of Consumer Research, 9 (2): 132-140. DOI: $10.1086 / 208906$.

Kenney M. and Zysman J. (2016). The Rise of the Platform Economy. Science and Technology, 32(3), http://issues.org/32-3/the-rise-of-the-platform-economy/.

Kogut B., Shan W. and Walker, G. (1992). The Make-Or-Cooperate Decision in the Context of an Industry Network. In: N. Nohria N. and Eccles R.E. (Eds.), Networks and Organizations, Cambridge, MA: Harvard Business School Press.

Lodigiani R. (2016) Alla base del welfare. Mutualismo e solidarietà nel settore della longterm care policies. Sociologia del Lavoro, 143: 95-111. DOI: 10.3280/SL2016-143006.

Maier F., Meyer M. and Steinbereithner M. (2014) Nonprofit Organizations Becoming Business-Like. Nonprofit \& Voluntary Sector Quarterly, 45(1): 64-86. https://doi.org/10.1177\%2F0899764014561796

McCole P. (2004). Refocusing marketing to reflect practice. Marketing Intelligence \& Planning, 22 (5): 531-539. DOI:10.1108/02634500410551914. 
Micheletti M., Hooghe M. and Stolle D. (2005). Politics in the Supermarket: Political Consumerism as a Form of Political Participation. International Political Science Review, 26 (3): 245-269.

Moulaert F., MacCallum D. and Hillier J. (2013b) 'Social Innovation: intuition, precept, concept, theory and practice' in Moulaert F., MacCallum D., Mehmood A. and Hamdouch (eds) The international handbook on Social Innovation. Collective action, Social Learning and Transdisciplinary Research. Cheltenham/Northampton: Edward Elgar.

Oosterlynck S., Y. Kazepov, A. Novy, P. Cools, E. Barberis, F. Wukovitsch, T. Sarius and B. Leubolt (2013). 'The butterfly and the elephant: local social innovation, the welfare state and new poverty dynamics'. IMPROVE Working No. 13/03. Published online https://goo.gl/XeJvX7, accessed 10 September 2018.

Parasuraman A., Zeithaml, V. and Berry, L. (1985). A Conceptual Model of Service Quality and its Implication for Future Research. Journal of Marketing, 49:41-50. DOI: $10.2307 / 1251430$.

Parsons T. (ed.) (1970). Knowledge and Society. American Sociology. New York: Basic Books.

Pol, E. and S. Ville, (2009), Social Innovation: Buzz Word or Enduring Term?. Journal of Socio-Economics, 38(i.): 878-885. https://doi.org/10.1016/j.socec.2009.02.011

Ritzer G. and Jungerson N. (2010).Production, Consumption, Prosumption. The nature of capitalism in the age of the digital prosumer. Journal of Consumer Culture. 10 (1):13-36. DOI: $10.1177 / 1469540509354673$.

Schor J. (2014). Debating sharing economy. In: The Great Transition Initiative, http://www.greattransition.org/

Stark D. (1996), Heterarchy: Asset Ambiguity, Organizational Innovation and the postsocialist Firm, CAHRS Working papers, n.21

Stark D., Watkins E.A. (2018). The Möbius Organizational Form: Make, Buy, Cooperate, or coo-opt? Sociologica, 12 (1):, 65-80.

Toffler A. (1980), The third wave, New York: Morrow.

Vargo S.L. and Lusch R.F. (2006). The Service-dominant Logic of Marketing: Dialogue, Debate, and Directions, Routledge: London.

Whatmore S., Stassart P. and Renting H. (2003). What's Alternative about Alternative Food Networks?. Environment and Planning 35 (3): 389-391. DOI: 10.1068/a3621.

Ziegler R. (2017) 'Social Innovation as a collaborative concept', in Innovation: The European Journal of Social Science Research, 30(4): 388-405. https://doi.org/10.1080/13511610.2017.1348935 